\title{
DAÑO GENÉTICO Y CITOTÓXICO PROVOCADO POR PLAGUICIDAS EN JORNALEROS QUE LABORAN EN INVERNADEROS EN ATLIXCO, PUEBLA, MÉXICO
}

\author{
(Genetic and cytotoxic damage induced by pesticides in greenhouse workers in Atlixco, Puebla, Mexico)
}

\begin{abstract}
Luis Daniel ORTEGA-MARTÍNEZ¹, Beatriz PÉREZ-ARMENDÁRIZ1 ${ }^{1}$, Stefan WALISZEWSKI², Sandra GÓMEZ-ARROYO ${ }^{3}$, Ma. del Rocío BAÑOS-LARA ${ }^{4}$, Marisol TERÁN-CERVANTES ${ }^{5}$, Gabriel CASTRO-CARRANZA ${ }^{5}$ y María del Carmen MARTÍNEZ-VALENZUELA ${ }^{5 *}$
\end{abstract}

${ }^{1}$ Universidad Popular Autónoma del Estado de Puebla, Departamento de Ciencias Biológicas, 11 Poniente 2316, Col. Barrio de Santiago, 72410 Puebla, Puebla, México

${ }^{2}$ Centro de Investigaciones Biomédicas, Universidad Veracruzana, Luis Castelazo, Col. Industrial Ánima, 91190 Xalapa, Veracruz, México

${ }^{3}$ Centro de Ciencias de la Atmósfera, Universidad Nacional Autónoma de México, Circuito de la Investigación Científica s/n, Ciudad Universitaria, Coyoacán, 04510 Ciudad de México, México

${ }^{4}$ Centro de Investigación Oncológica Una Nueva Esperanza, Universidad Popular Autónoma del Estado de Puebla, Venustiano Carranza 504, Reserva Territorial Atlixcáyotl, Concepción la Cruz, 72197 Puebla, Puebla, México

${ }^{5}$ Unidad de Investigación en Ambiente y Salud, Universidad Autónoma de Occidente, Bulevar Macario Gaxiola y Carretera Internacional, 81223 Los Mochis, Sinaloa, México

*Autora para correspondencia: camava9@gmail.com

(Recibido mayo 2017; aceptado junio 2018)

Palabras clave: exposición ocupacional, anormalidades nucleares, frecuencias de micronúcleos

\section{RESUMEN}

El monitoreo del daño genotóxico en jornaleros de invernaderos permite identificar el deterioro del ADN originado por las condiciones laborales. Se ha sugerido el empleo de diferentes marcadores biológicos para evaluar el riesgo de exposición ocupacional y el daño al ADN, uno de los cuales es el ensayo de micronúcleos (MN). El objetivo del estudio fue determinar la frecuencia de MN y anormalidades nucleares en frotis epiteliales de mucosa bucal de 40 jornaleros de invernaderos de alta y baja tecnología, expuestos a distintas clases de plaguicidas, y en 40 personas no expuestas a estos compuestos. Ambas poblaciones residen en la ciudad de Atlixco, Puebla, México. Las muestras tomadas se secaron al aire y se fijaron con metanol-ácido acético, después se tiñeron mediante la reacción de Feulgen. Se evaluaron las anormalidades nucleares contando mil células basales diferenciadas por participante. La comparación de frecuencias de los biomarcadores indicó mayor valor estadísticamente significativo de anormalidades nucleares en jornaleros de invernaderos, cuyas relaciones de índice de frecuencia fueron: 63.0 células binucleadas, 14.2 células con cromatina condensada, 8.0 células cariolíticas, 3.8 células picnóticas, 2.4 células con brotes nucleares y 2.3 células con micronúcleos. La frecuencia mayor de anormalidades nucleares se determinó en jornaleros que laboran en invernaderos de baja tecnología en comparación con los invernaderos de alta tecnología. La población masculina de invernaderos de baja tecnología mostró mayores frecuencias de células picnóticas, con micronúcleos y con brotes nucleares. 
Key words: occupational exposition, nuclear abnormalities, micronuclei frequency

\begin{abstract}
The monitoring of genotoxic damage in laborers of greenhouses allows the identification of deterioration of DNA originated by working conditions. It has been suggested the use of different biological markers to evaluate the risk of occupational exposure and DNA damage, one of them is the micronucleus (MN) assay. The objective of the study was to determine the frequency of $\mathrm{MN}$ and nuclear abnormalities in the buccal mucosa epithelium of 40 workers of high and low technology greenhouses, who are exposed to diferent kinds of pesticides, and of 40 people not exposed to these compounds, both populations from Atlixco City, in Puebla, Mexico. The samples taken were air-dried and fixed with methanol-acetic acid. Later they were stained by the Feulgen reaction. Nuclear abnormalities were assessed by counting one thousand differentiated basal cells per participant. Comparison of biomarkers frequencies indicates higher values of nuclear abnormalities statistically significant in laborers of greenhouses, whose frequency index ratios were: 63.0 binucleate cells, 14.2 cells with condensed chromatin, 8.0 cariolitic cells, 3.8 cells pycnotic, 2.4 cells with nuclear outbreaks, and 2.3 cells with micronuclei. The highest frequency of nuclear abnormalities was determined in laborers working in low-tech greenhouses compared to high-tech greenhouses. The male population of low-tech greenhouses showed higher frequencies of pycnotic cells, micronuclei, and cells with nuclear outbreaks.
\end{abstract}

\section{INTRODUCCIÓN}

La agricultura protegida es un sistema de producción agrícola en el que destacan los invernaderos, los cuales se clasifican en niveles bajo, medio y alto grado de acuerdo con las tecnologías que se implementan en ellos, como películas plásticas, sustratos, sistemas de producción y automatización climática (García et al. 2011). Las tecnologías influyen principalmente en las condiciones ambientales generadas en el interior del invernadero, ya que se crean las óptimas y apropiadas de radiación, temperatura, humedad, dióxido de carbono y circulación de aire para la reproducción, desarrollo y crecimiento de las plantas, así como el aumento de producción (Castañeda et al. 2007). Asimismo, dichas condiciones favorecen el crecimiento, desarrollo y propagación de organismos tanto benéficos como perjudiciales, los cuales pueden manifestarse como plagas y enfermedades que implican mayor riesgo económico. Por ello el productor recurre de manera continua a plaguicidas para eliminarlas (Sonneveld y Voogt 2009, Salazar et al. 2012).

Debido a sus condiciones sociales y culturales, los jornaleros que laboran en invernaderos no respetan o desconocen las instrucciones sobre el uso y manejo de plaguicidas, o bien minimizan su riesgo para la salud; esto, aunado a que el invernadero es un espacio cerrado con escasa circulación de aire y volatilización de agroquímicos, lo que aumenta la exposición, riesgo y probabilidad de afectación para su salud (Haro-García et al. 2002, Bortoli et al. 2009, Ortega-Martínez et al. 2014). La constante exposición a vapores y residuos de plaguicidas presentes en el ambiente del invernadero, que son espacios cerrados, favorecen el proceso de absorción de sustancias tóxicas a través de su inhalación, absorción dérmica o ingestión, la que puede originar el daño citogenético (Costa et al. 2006, Peralta et al. 2011).

Diversos estudios de monitoreo de jornaleros de invernaderos expuestos laboralmente a plaguicidas, utilizaron variedad de biomarcadores nucleares de exposición, como aberraciones cromosómicas, micronúcleos, intercambio de cromátidas hermanas y el ensayo cometa, encontrando resultados positivos (Costa et al. 2006, Peralta et al. 2011 Gómez-Arroyo et al. 2000,2013), así como resultados negativos de la exposición (Lucero et al. 2000, Piperakis et al. 2003, 2006, Lamadrid et al. 2011). Las diferencias en los resultados pueden asociarse a extensas fuentes de variabilidad ocasionadas principalmente por el implemento de tecnologías en el invernadero que modifican las condiciones ambientales, el comportamiento de los plaguicidas y la exposición de los jornaleros, en comparación con un sistema de cultivo convencional en el que la degradación o dispersión de vapores de 
plaguicidas es más rápida por la radiación solar, el aire y la lluvia (Sonneveld y Voogt 2009, Bojacá et al. 2013, Wu et al. 2013).

El objetivo de este trabajo fue determinar el daño citogenético en las células epiteliales de exfoliación bucal a través del ensayo de micronúcleos, evaluando las frecuencias de anormalidades nucleares en personas no expuestas y expuestas a los plaguicidas en invernaderos de alta y baja tecnología en Atlixco, Puebla, México.

\section{MATERIALES Y MÉTODOS}

El estudio se desarrolló en el municipio de Atlixco, localizado en el centro-oeste del estado de Puebla, a una altitud promedio de $1840 \mathrm{msnm}$, entre las coordenadas $18^{\circ} 49^{\prime} 30^{\prime \prime}-18^{\circ} 58^{\prime} 30^{\prime \prime} \mathrm{N}$ y $98^{\circ} 18^{\prime}$ $24^{\prime \prime}-98^{\circ} 33^{\prime} 36^{\prime \prime} \mathrm{O}$. El criterio para seleccionar a los jornaleros se basó en el inventario de invernaderos del estado de Puebla (INEGI 2008).

Los invernaderos seleccionados representaron una superficie de 5000 y $7000 \mathrm{~m}^{2}$ de sembradío para la producción de jitomate con baja y alta tecnología, respectivamente, de acuerdo con la clasificación de García et al. (2010). Los grupos de estudio se formaron con 40 jornaleros (16 mujeres y 24 hombres) con una edad promedio de $32.9 \pm 8.0$ años, los cuales laboraron en invernaderos con antigüedad de 3 a 4 años y aceptaron voluntariamente participar en el estudio. Por otra parte, el grupo no expuesto estuvo constituido por 40 individuos (16 mujeres y 24 hombres) no involucrados en labores del invernadero ni en el uso y aplicación de plaguicidas, con una edad promedio de $30.1 \pm 10.3$ años. Todos los participantes fueron informados sobre el objetivo del estudio y firmaron el consentimiento de participación. El estudio fue aprobado por el Comité de Ética de la Universidad Popular Autónoma del Estado de Puebla.

A los participantes se les solicitó enjuagarse la boca con agua y se les realizó un raspado de la parte interna de las mejillas con una espátula estéril para recolectar las células epiteliales de descamación, las cuales se colocaron en laminillas previamente codificadas para evitar el sesgo durante el conteo y se dejaron secar al aire libre. Posteriormente, las células se fijaron con una mezcla de metanol-ácido acético (3:1). La hidrolización del ADN y su tinción se realizaron mediante la reacción de Feulgen. Las anormalidades nucleares se clasificaron de acuerdo con los criterios de Stich y Rosin (1984), Stich (1987), Tolbert et al. (1992), Martínez-Valenzuela et al. (2009), Thomas et al. (2009) y Bolognesi y
Fenech (2013). Las observaciones en el microscopio de campo claro se realizaron sobre las células con núcleos bien definidos entre 1000 células diferenciadas de cada muestra, con el fin de determinar la frecuencia de micronúcleos y otras anormalidades nucleares como picnosis, cromatina condensada, brotes nucleares, cariolisis y células binucleadas. Las células degeneradas no se contaron para el estudio.

\section{Análisis estadístico}

Los datos de las frecuencias de anormalidades nucleares se calcularon aplicando la estadística descriptiva con la media aritmética \pm error estándar $(\mathrm{X} \pm \mathrm{EE})$, así como el índice de frecuencia (IF), que expresan la diferencia de frecuencias entre jornaleros expuestos y el grupo no expuesto. La diferencia en la magnitud de anormalidades nucleares entre los grupos de jornaleros expuestos en invernaderos con alta tecnología y sin tecnología, se determinó mediante la prueba paramétrica $t$ de Student, cuyos valores se consideraron significativos cuando $\mathrm{p}<0.05$. La normalidad de los datos se analizó con el método de Shapiro-Wilk, y pasaron la prueba aquellos con valores de $\mathrm{p}<0.05$. El análisis estadístico se realizó con el programa estadístico Minitab versión 12.

\section{RESULTADOS}

Los ingredientes activos de los principales plaguicidas empleados en los invernaderos son los clasificados como ligeramente peligrosos (Cuadro I). Sin embargo, los de baja tecnología incluyen imidacloprid, una sustancia altamente peligrosa que se utiliza principalmente en insecticidas y funguicidas para el control de la mosquita blanca (Bemisia tabaco) y de podredumbre gris (Botrytis cinérea).

No se observaron diferencias entre las edades de ambos grupos. El grupo de jornaleros presentó una edad de $32.9 \pm 8.0$ años en comparación con el grupo no expuesto $(30.1 \pm 10.3$ años), sin diferencia estadísticamente significativa $(\mathrm{p}>0.05)$. Al analizar los valores de anormalidades nucleares en células epiteliales bucales entre los jornaleros comparados con los testigos, las frecuencias más altas de anormalidades correspondieron a los jornaleros de los invernaderos, las cuales fueron estadísticamente significativas ( $\mathrm{p}$ $<0.05$ ). Para comparar el efecto de la exposición a vapores de agroquímicos presentes en el lugar laboral entre los jornaleros y el grupo testigo, se calculó el IF en las anormalidades nucleares. Los resultados se presentan en el cuadro II. 
CUADRO I. PRINCIPALES INGREDIENTES ACTIVOS UTILIZADOS EN INVERNADEROS PARA LA PRODUCCIÓN DE TOMATE DURANTE EL CICLO AGRÍCOLA 2016

\begin{tabular}{lcc}
\hline Ingrediente activo & Tipo & $\begin{array}{c}\text { Clasificación } \\
\text { de peligrosidad }\end{array}$ \\
\hline Metalaxil-M + mancozeb & $\mathrm{F}$ & $\mathrm{III}$ \\
Carbendazim: metilbenzimidazol-2-il carbamato & $\mathrm{F}$ & $\mathrm{IV}$ \\
Polisacáridos, microorganismos y extractos halogenados, & & \\
polihidroxicarbónicos, quillaja, Paecilomyces lilacinus & $\mathrm{N}$ & $\mathrm{IV}$ \\
Imidacloprid & $\mathrm{I}$ & $\mathrm{II}$ \\
Alga marina eklonia máxima, & & \\
ácido indol-3-butírico (4-(1 H-indol-3-yl) butyric acid) & $\mathrm{RCV}$ & $\mathrm{IV}$ \\
Azaridactina & $\mathrm{I}$ & $\mathrm{IV}$ \\
Flubendiamide & $\mathrm{I}$ & $\mathrm{III}$ \\
Spirotetramat & $\mathrm{I}$ & $\mathrm{IV}$ \\
Clorotalonil & $\mathrm{F}$ & $\mathrm{IV}$ \\
Sulfato de cobre pentahidratado & $\mathrm{F}$ & $\mathrm{IV}$ \\
Cymoxanil + hidroxico cuprico & $\mathrm{F}$ & $\mathrm{IV}$ \\
Extracto de Larrea tridentata L. & $\mathrm{B} / \mathrm{F}$ & $\mathrm{IV}$ \\
Dióxido de cloro & $\mathrm{D}$ & $\mathrm{IV}$ \\
& &
\end{tabular}

F: funguicida, B: bactericida, N: nematicida, I: insecticida, RCV: regulador de crecimiento vegetal. Clasificación de peligrosidad según la Organización Mundial de la Salud (WHO 2009): I: extremadamente peligroso, II: altamente peligroso, III: moderadamente peligroso, IV: ligeramente peligroso

CUADRO II. ÍNDICE DE FRECUENCIAS (IF) DE ANORMALIDADES NUCLEARES ENTRE 40 INDIVIDUOS EXPUESTOS A PLAGUICIDAS EN INVERNADEROS Y 40 PARTICIPANTES NO EXPUESTOS

\begin{tabular}{lcrrr}
\hline Variable & $\begin{array}{c}\text { No } \\
\text { expuestos } \\
(\mathrm{X})\end{array}$ & $\begin{array}{c}\text { Expuestos } \\
(\mathrm{X})\end{array}$ & $\begin{array}{c}\text { Prueba t } \\
\text { de student } \\
(\mathrm{p})\end{array}$ & IF \\
& 1.9 & 4.4 & $0.000^{*}$ & 2.3 \\
\hline Micronúcleos & 23.3 & 88.8 & $0.000^{*}$ & 3.8 \\
$\begin{array}{l}\text { Picnosis } \\
\text { Condensación }\end{array}$ & & & & \\
cromatina & 9.8 & 138.7 & $0.000^{*}$ & 14.2 \\
Brotes nucleares & 3.4 & 8.0 & $0.000^{*}$ & 2.4 \\
$\begin{array}{l}\text { Cariolisis } \\
\text { Células binucleadas }\end{array}$ & 1.6 & 12.8 & $0.006^{*}$ & 8.0 \\
\hline
\end{tabular}

X: media aritmética

*Diferencia estadísticamente significativa con $\mathrm{p}<0.05$

Para diferenciar los factores que definen las condiciones laborales en los invernaderos, considerando el uso de alta tecnología (20 jornaleros) y baja tecnología (20 jornaleros), se dividió el grupo total de acuerdo a este factor. Los resultados de la evaluación estadística se presentan en el cuadro III para el grupo de jornaleros que laboraron en invernaderos con alta tecnología y en el cuadro IV para los que laboraron en invernaderos de baja tecnología. La comparación de ambos grupos de jornaleros se presenta en el cuadro $\mathbf{V}$.

Para evaluar el factor de género como indicador de exposición a los vapores de plaguicidas en los invernaderos con alta tecnología y baja tecnología, las poblaciones se dividieron de acuerdo a esta variable. Los resultados con las diferencias calculadas, se presentan en los cuadros VI y VII.

\section{DISCUSIÓN}

La exposición ocupacional puede relacionarse con el desarrollo de diferentes padecimientos inducidos por los mecanismos que residen en cambios de cromosomas (Martino-Roth et al. 2003). La exposición medida con la magnitud de anormalidades nucleares, expresa el tamaño de exposición y su prevalencia en las personas expuestas (Srám y Binková 2000). Uno de los biomarcadores de irregular división celular que involucra el rompimiento de cromosomas, inadecuada segregación de cromatina o las interferencias en mitosis, es la formación de micronúcleos y otras anormalidades nucleares. La frecuencia de estos eventos observados en células epiteliales bucales puede constatar el tamaño de la exposición (Holland et al. 2008), ya que el aumento 
CUADRO III. ÍNDICE DE FRECUENCIAS (IF) DE ANORMALIDADES NUCLEARES ENTRE INDIVIDUOS EXPUESTOS A PLAGUICIDAS EN INVERNADEROS CON ALTA TECNOLOGÍA $(\mathrm{n}=20)$ E INDIVIDUOS NO EXPUESTOS $(\mathrm{n}=40)$

\begin{tabular}{lcccc} 
Variable & $\begin{array}{c}\text { No expuestos } \\
(\mathrm{X})\end{array}$ & $\begin{array}{c}\text { Invernaderos con alta } \\
\text { tecnología }(\mathrm{X})\end{array}$ & $\begin{array}{c}\text { Prueba } \\
\text { t de Student (p) }\end{array}$ & IF \\
Micronúcleos & 1.9 & 2.5 & 0.133 & 1.3 \\
Picnosis & 23.3 & 41.9 & $0.017^{*}$ & 1.8 \\
Condensacion de cromatina & 9.8 & 47.4 & $0.001^{*}$ & 4.8 \\
Brotes nucleares & 3.4 & 4.3 & 0.382 & 1.3 \\
Cariolisis & 1.6 & 13.3 & $0.000^{*}$ & 8.3 \\
Celulas binucleadas & 1.6 & 125.8 & $0.000^{*}$ & 7.9 \\
\hline
\end{tabular}

$\mathrm{X}$ : media aritmética

*Diferencia estadísticamente significativa con $\mathrm{p}<0.05$

CUADRO IV. ÍNDICE DE FRECUENCIAS (IF) DE LAS ANORMALIDADES NUCLEARES ENTRE INDIVIDUOS EXPUESTOS A PLAGUICIDAS EN INVERNADEROS DE BAJA TECNOLOGÍA $(\mathrm{n}=20)$ E INDIVIDUOS NO EXPUESTOS $(\mathrm{n}=40)$

\begin{tabular}{lcccr}
\hline Variable & $\begin{array}{c}\text { No } \\
\text { expuestos }(\mathrm{X})\end{array}$ & $\begin{array}{c}\text { Invernaderos con } \\
\text { baja tecnología }(\mathrm{X})\end{array}$ & $\begin{array}{c}\text { Prueba } \\
\text { t de Student }(\mathrm{p})\end{array}$ & IF \\
\hline Micronúcleos & 1.9 & 6.8 & $0.000^{*}$ & 3.6 \\
Picnosis & 23.3 & 139.5 & $0.001^{*}$ & 6.0 \\
Condensación de cromatina & 9.8 & 242.1 & $0.000^{*}$ & 24.7 \\
Brotes nucleares & 3.4 & 11.4 & $0.004^{*}$ & 3.4 \\
Cariolisis & 1.6 & 12.3 & $0.000^{*}$ & 7.7 \\
Células binucleadas & 1.6 & 74.8 & $0.000^{*}$ & 46.8 \\
\hline
\end{tabular}

$\mathrm{X}$ : media aritmética

*Diferencia estadísticamente significativa con $\mathrm{p}<0.05$

CUADRO V. COMPARACIÓN DEL ÍNDICE DE FRECUENCIAS (IF) DE ANORMALIDADES NUCLEARES ENTRE INDIVIDUOS EXPUESTOS A PLAGUICIDAS EN INVERNADEROS CON BAJA TECNOLOGÍA Y AQUELLOS CON ALTA TECNOLOGÍA

\begin{tabular}{lcccc}
\hline Variable & $\begin{array}{c}\text { Expuestos en invernaderos con } \\
\text { baja tecnología }(X)\end{array}$ & $\begin{array}{c}\text { Expuestos en invernaderos } \\
\text { con alta tecnología (X) }\end{array}$ & $\begin{array}{c}\text { Prueba } \\
\text { t de Student (p) }\end{array}$ & IF \\
\hline Micronúcleos & 6.8 & 2.5 & $0.000^{*}$ & 2.7 \\
Picnosis & 139.5 & 41.9 & $0.003^{*}$ & 3.2 \\
Condensación de cromatina & 242.1 & 47.4 & $0.000^{*}$ & 5.1 \\
Brotes nucleares & 11.4 & 4.3 & $0.010^{*}$ & 2.7 \\
Cariolisis & 12.3 & 13.3 & 0.731 & 0.9 \\
Células binucleadas & 74.8 & 125.8 & $0.016^{*}$ & 0.6 \\
\hline
\end{tabular}

$\mathrm{X}$ : media aritmética

*Diferencia estadísticamente significativa con $\mathrm{p}<0.05$

de frecuencias en anormalidades nucleares puede relacionarse con el paso temprano en la carcinogénesis (Bonassi et al. 2011).

Los resultados de nuestro estudio con individuos expuestos a plaguicidas en invernaderos coinciden con los descritos por Bortoli et al. (2009),
Martínez-Valenzuela et al. (2009), Larrea-Poma et al. (2010), Kvitko et al. (2012), Benedetti et al. (2013) y Carbajal-López et al. (2016), quienes encuentran un incremento significativo en las frecuencias de células binucleadas, cromatina condensada y células cariolíticas en trabajadores expuestos en comparación 
CUADRO VI. COMPARACIÓN DEL ÍNDICE DE FRECUENCIAS (IF) DE ANORMALIDADES NUCLEARES ENTRE INDIVIDUOS EXPUESTOS A PLAGUICIDAS DE GÉNERO MASCULINO $(\mathrm{M}, \mathrm{n}=8)$ Y FEMENINO $(\mathrm{F}, \mathrm{n}=12)$ QUE LABORAN EN INVERNADEROS CON ALTA TECNOLOGÍA

\begin{tabular}{lrrrc}
\hline Variable & $\mathrm{X} \pm \mathrm{EE}(\mathrm{M})$ & $\mathrm{X} \pm \mathrm{EE}(\mathrm{F})$ & Prueba t de Student $(\mathrm{p})$ \\
\hline $\mathrm{MN}$ & $2.7 \pm 0.4$ & $2.3 \pm 0.4$ & 0.581 \\
Picnosis & $56.8 \pm 11.6$ & $30.7 \pm 6.6$ & 0.073 \\
Condensación de cromatina & $40.3 \pm 12.1$ & $52.7 \pm 14.9$ & 0.528 \\
Brotes nucleares & $4.9 \pm 1.1$ & $3.8 \pm 0.8$ & 0.444 \\
Cariolisis & $15.7 \pm 3.1$ & $11.6 \pm 2.4$ & 0.308 \\
Células binucleadas & $113.3 \pm 16.4$ & $135.1 \pm 19.6$ & 0.406 \\
\hline
\end{tabular}

$\mathrm{X} \pm \mathrm{EE}:$ media aritmética \pm error estándar

CUADRO VII. COMPARACIÓN DEL ÍNDICE DE FRECUENCIAS (IF) DE LAS ANORMALIDADES NUCLEARES ENTRE INDIVIDUOS EXPUESTOS A PLAGUICIDAS DE GÉNERO MASCULINO $(\mathrm{M}, \mathrm{n}=12)$ Y FEMENINO $(\mathrm{F}, \mathrm{n}=8)$ QUE LABORAN EN INVERNADEROS CON BAJA TECNOLOGÍA

\begin{tabular}{lrrc}
\hline Variable & $\mathrm{X} \pm \mathrm{EE}(\mathrm{M})$ & $\mathrm{X} \pm \mathrm{EE}(\mathrm{F})$ & Prueba t de Student $(\mathrm{p})$ \\
\hline $\mathrm{MN}$ & $8.6 \pm 1.3$ & $4.4 \pm 0.7$ & $0.014^{*}$ \\
Picnosis & $189.7 \pm 42.7$ & $72.6 \pm 22.2$ & $0.027^{*}$ \\
Condensación de cromatina & $242.8 \pm 42.1$ & $241.1 \pm 53.9$ & 0.980 \\
Brotes nucleares & $15.1 \pm 3.8$ & $6.4 \pm 1.3$ & $0.053^{*}$ \\
Cariolisis & $11.2 \pm 2.1$ & $13.9 \pm 4.4$ & 0.585 \\
Células. binucleadas & $53.2 \pm 15.4$ & $103.6 \pm 27.6$ & 0.136 \\
\hline
\end{tabular}

$\mathrm{X} \pm \mathrm{EE}$ : media aritmética \pm error estándar

*Diferencias estadísticamente significativas

con los testigos, que corresponden a personas no involucradas en la aplicación de plaguicidas. Este incremento de anormalidades nucleares es principalmente resultado de la continua exposición a plaguicidas rociados en invernaderos y aspirados por los trabajadores. Los estudios referidos muestran sólo un incremento de células con anormalidades nucleares, mientras que las frecuencias de anormalidades nucleares en nuestro estudio fueron pronunciadas y tuvieron significancia estadística mayor.

El análisis de frecuencias de anormalidades nucleares que toma en cuenta el factor de uso de tecnología aplicada en los invernaderos, el cual al mismo tiempo refleja la educación de los jornaleros para laborar en condiciones insalubres y manejar el plaguicida con precaución, indica aumentos moderados de células cariolíticas, células binucleadas y con cromatina condensada en comparación con el grupo de testigo.

La comparación de los IF de anormalidades nucleares entre individuos que laboran en invernaderos con alta y baja tecnología evidencia frecuencias superiores en el caso de invernaderos de baja tecnología, con resultados similares a los de Bolognesi et al. (2004), quienes mencionan un aumento de anormalidades por mayor exposición a plaguicidas. El aumento de frecuencias de anormalidades nucleares en la mucosa normal, observado en las lesiones precancerosas y en el carcinoma sugirió un vínculo de este biomarcador con la progresión neoplásica causada por múltiples factores que incluyen la exposición a vapores de plaguicidas inhalados durante la jornada laboral (Casartelli et al. 2000). La presencia de micronúcleos en células de exfoliación bucal es un evento relativamente raro, cuya frecuencia es de una célula con micronúcleos por cada 1000 células de descamación con una variabilidad individual específica (Ceppi et al. 2010). Se han reportado frecuencias de 0.5 a $2.5 \mathrm{MN} / 1000$ células (Kashyap et al. 2012). En nuestro estudio, el valor promedio del grupo testigo fue de $1.9 \mathrm{MN} / 1000$ células, valor que se encuentra dentro de los reportados.

Los datos sugieren que los efectos genotóxicos se incrementan en los tejidos linfoides y epiteliales a 
causa de la exposición al mutágeno o de una enfermedad degenerativa. Los defectos hereditarios en el mantenimiento del genoma son sistémicos y se producen en todos los tejidos. Por consiguiente, se considera que las diferencias en la cinética de replicación y la vida media de células bucales no pueden afectar a la expresión de las frecuencias en anormalidades nucleares. Además, las diferencias pierden importancia en condiciones de exposición crónica, la cual conduce a un estado de equilibrio con un elevado nivel de expresión independientemente de la tasa de división celular, cuando el periodo de exposición excede el marco de tiempo para una división nuclear (Fenech et al. 2011). Los carcinógenos del tracto aerodigestivo aumentan la frecuencia de anormalidades nucleares tanto en las células bucales como de linfocitos, debido a que llegan principalmente a la corriente sanguínea, presentando un efecto sistémico para los tejidos. Finalmente, en células bucales, las anormalidades nucleares se expresan en las células basales en división de las capas profundas de la mucosa bucal (Ceppi et al. 2010). Otros factores que valoran el ensayo del citoma y la frecuencia de células basales, células binucleadas, brotes nucleares, células picnóticas, células cariolíticas y células con cromatina condensada, se desarrollaron con menor frecuencia. Cabe señalar que en nuestro estudio el criterio de valoración (proporción de células binucleadas, células con cromatina condensada, células cariolíticas, células picnóticas, células con brotes nucleares y con micronúcleos) reveló valores elevados que llaman la atención como indicadores de riesgo laboral con las consecuentes afectaciones para la salud.

El comportamiento en casos de anormalidades nucleares puede explicarse por los factores de una desigual exposición a genotóxicos exógenos procedentes del ambiente ocupacional y diferente respuesta entre los géneros; no obstante, los resultados difieren a los de Lucero et al. (2000), quienes indicaron que no encontraron diferencias estadísticamente significativas entre trabajadores de invernaderos expuestos a plaguicidas y los no expuestos.

En casos de exposición crónica, las diferencias entre la cinética de replicación y la vida media entre células bucales puede afectar la aparición de anormalidades nucleares en la mucosa bucal, ya que dicha exposición crónica conduce a una expresión elevada en estado estacionario de estas anormalidades, independiente de la tasa de división celular, si el periodo de exposición excede el tiempo necesario para una división nuclear (Ceppi et al. 2010). Al comparar en este estudio a los individuos expuestos a plaguicidas con el grupo no expuesto, el daño al
ADN se observa como consecuencia del contacto con los vapores de plaguicidas que persisten en los invernaderos, cuya magnitud podría depender de la tecnificación de los invernaderos para la producción agrícola.

\section{CONCLUSIONES}

Nuestros resultados proporcionan información sobre las frecuencias de anormalidades nucleares y citotoxicidad originada por el uso de plaguicidas en los invernaderos y el trabajo en condiciones de gran exposición a sus vapores. La combinación del grado de alteraciones nucleares específicas en las células bucales con el desarrollo de diversas enfermedades, puede desempeñar un papel importante en la identificación de individuos con alto riesgo de desarrollar enfermedades laborales; asimismo, pone de manifiesto que los individuos que laboran en invernaderos mostraron una mayor frecuencia de células con anormalidades nucleares, debido al efecto citotóxico de la exposición a los plaguicidas. La investigación de daños al ADN es un proceso necesario para evaluar la calidad del ambiente laboral, así como una herramienta para la educación de los trabajadores con el objetivo de disminuir el daño genético y prevenir el riesgo de enfermedades graves.

\section{REFERENCIAS}

Benedetti D., Nunes E., Sarmento M., Porto C., Iochims dos Santos C.E., Ferraz Dias J. y da Silva J. (2013). Genetic damage in soybean workers exposed to pesticides: Evaluation with the comet and buccal micronucleus cytome assays. Mutat. Res. 752 (1-2), 28-33. DOI: 10.1016/j.mrgentox.2013.01.001

Bojacá C.R., Arias L.A., Ahumada D.A., Casilimas H.A. y Schrevens E. (2013). Evaluation of pesticide residues in open field and greenhouse tomatoes from Colombia. Food Control 30, 400-403.

DOI: 10.1016/j.foodcont.2012.08.015

Bolognesi C., Landini E., Perrone E. y Roggieri P. (2004). Cytogenetic biomonitoring of a floriculturist population in Italy: Micronucleus analysis by fluorescence in situ hybridization (FISH) with an all-chromosome centromeric probe. Mutat. Res. 557, 109-107.

DOI: 10.1016/j.mrgentox.2003.09.013

Bolognesi C. y Fenech M. (2013). Micronucleus assay in human cells: lymphocytes and buccal cells. Methods Mol. Biol. 1044, 191-207.

DOI: $10.1007 / 978-1-62703-529-3 \_10$ 
Bonassi S., El-Zein R., Bolognesi C. y Fenech M. (2011). Micronuclei frequency in peripheral blood lymphocytes and cancer risk: Evidence from human studies. Mutagenesis 26 (1), 93-100.

DOI: $10.1093 /$ mutage/geq075

Bortoli G.M., Azevedo M.B. y Silva L.B. (2009). Cytogenetic biomonitoring of Brazilian workers exposed to pesticides: micronucleus analysis in buccal epithelial cells of soybean growers. Mutat. Res. 675 (1-2), 1-4. DOI: 10.1016/j.mrgentox.2009.01.001

Carbajal-López Y., Gómez-Arroyo S., Villalobos-Pietrini R., Calderón-Segura M.E. y Martínez-Arroyo A. (2016). Biomonitoring of agricultural workers exposed to pesticide mixtures in Guerrero state, Mexico with comet assay and micronucleus test. Environ. Sci. Pollut. Res. 23 (3), 2513-21520.

DOI: $10.1007 / \mathrm{s} 11356-015-5474-7$

Casartelli G., Bonatti S., de Ferrari M., Scala M., Mereu P., Margarino G. y Abbondandolo A. (2000). Micronucleus frequencies in exfoliated buccal cells in normal mucosa, precancerous lesions and squamous cell carcinoma. Anal. Quant. Cytol. Histol. 22 (6), 486-492.

Castañeda-Miranda R., Ventura-Ramos E., Peniche-Vera R. y Herrera-Ruiz G. (2007). Análisis y simulación del modelo físico de un invernadero bajo condiciones climáticas de la región central de México. Agrociencia 41 (3), 317-335.

Ceppi M., Biasotti B., Fenech M. y Bonassi S. (2010). Human population studies with the exfoliated buccal micronucleus assay: statistical and epidemiological issues. Mutat. Res. Rev. Mutat. 705 (1), 11-19.

DOI: 10.1016/j.mrrev.2009.11.001

Costa C., Teixeira J.P., Silva S., Roma T.J., Coelho P., Gaspar J., Alves M., Laffon B., Rueff J. y Mayan O. (2006). Cytogenetic and molecular biomonitoring of a Portuguese population exposed to pesticides. Mutagenesis 21 (5), 343-350.

DOI: $10.1093 /$ mutage/gel039

Fenech M., Kirsch V.M., Natarajan A.T., Surralles J., Crott J.W., Parry J., Norppa H., Eastmond D.A., Tucker J.D. y Thomas P. (2011). Molecular mechanisms of micronucleus, nucleoplasmic bridge and nuclear bud formation in mammalian and human cells. Mutagenesis 26 (1), 125-132. DOI: 10.1093/mutage/geq052

García M.C., Balasch S.F., Alcon M.A. y Fernández Z. (2010). Characterization of technological levels in Mediterranean horticultural greenhouses. Span. J. Agric. Res. 8 (3), 509-525.

DOI: $10.5424 / \mathrm{sjar} / 2010083-1247$

García E.I., Aguilar Á.J. y Bernal M.R. (2011). La agricultura protegida en Tlaxcala, Méjico: La adopción de innovaciones y el nivel de equipamiento como factores para su categorización. Revista Latinoamericana de Investigación en Organizaciones, Ambiente y Sociedad 2,193-212.

Gómez-Arroyo S., Díaz-Sánchez Y., Meneses-Pérez M.A., Villalobos-Pietrini R. y de León-Rodríguez J. (2000). Cytogenetic biomonitoring in a Mexican floriculture worker group exposed to pesticides. Mutat. Res. 466 (1), 117-124. DOI: $10.1016 / \mathrm{S} 1383-5718(99) 00231-4$

Gómez-Arroyo S., Martínez-Valenzuela C., CarbajalLópez Y., Martínez-Arroyo A., Calderón-Segura M.E., Villalobos-Pietrini R. y Waliszewski S.M. (2013). Riesgo genotóxico por la exposición ocupacional a plaguicidas en América Latina. Rev. Int. Contam. Ambie. 29, 159-180.

Haro-García L., Chaín-Castro T., Barrón-Aragón R. y Bohórquez-López A. (2002). Efectos de plaguicidas agroquímicos: Perfil epidemiológico-ocupacional de trabajadores expuestos. Rev. Med. Inst. Mex. Seguro Soc. 40 (1), 19-24.

Holland N., Bolognesi C., Kirsch-Volders M., Bonassi S., Zeiger E., Knasmueller S. y Fenech M. (2008). The micronucleus assay in human buccal cells as a tool for biomonitoring DNA damage: The HUMN project perspective on current status and knowledge gaps. Mutat. Res. Rev. Mutat. 659 (1), 93-108.

DOI: $10.1016 /$ j.mrrev.2008.03.007

INEGI (2008). Censo agropecuario 2007. VIII censo agrícola, ganadero y forestal. Instituto Nacional de Estadística y Geografía [en línea]. http://www3.inegi.org. $\mathrm{mx} /$ contenidos/proyectos/agro/agricola/2007/tabulados/ Tabulado_Mpio_VIII_CAGyF_24_21.pdf 21/05/2017

Kashyap B. y Reddy P.S. (2012). Micronuclei assay of exfoliated oral buccal cells: Means to assess the nuclear abnormalities in different diseases. J. Canc. Res. Ther. 8 (2), 184-191. DOI: 10.4103/0973-1482.98968

Kvitko K., Bandinelli E., Henriquez J.A.P., Heuser V.D., Rohr P., da Silva F.R., Balzan Schneider N., Fernandes S., Ancines C. y da Silva J. (2012). Susceptibility to DNA damage in workers occupationally exposed to pesticides, to tannery chemicals and to coal dust during mining. Gen. Mol. Biol. 35, 1060-1068.

DOI: $10.1590 /$ S1415-47572012000600022

Lamadrid B.A.I., Romero A.I., González M.J.E. y Mandina C.T. (2011). Biomonitoreo de trabajadores expuestos a plaguicidas. Rev. Cubana Inv. Biomed. 30 (2), 235-244.

Larrea-Poma M., Tirado-Bustillos N. y Ascarrunz G.M.E. (2010). Daño genotóxico por exposición a plaguicidas en agricultores del Municipio de Luribay. BIOFARBO 18 (2), 31-43.

Lucero L., Pastor S., Suárez S., Durbán R., Gómez C., Parrón T., Creus A. y Marcos R. (2000). Cytogenetic 
biomonitoring of Spanish greenhouse workers exposed to pesticides: Micronuclei analysis in peripheral blood lymphocytes and buccal epithelial cells. Mutat. Res. 464 (2), 255-262.

DOI: $10.1016 /$ S1383-5718(99)00200-4

Martínez-Valenzuela C., Gómez-Arroyo S., VillalobosPietrini R., Waliszewski S., Calderón-Segura M.E., Félix-Gastélum R. y Álvarez-Torres A. (2009). Genotoxic biomonitoring of agricultural workers exposed to pesticides in the north of Sinaloa State, Mexico. Environ. Int. 35 (8), 1155-1159.

DOI: $10.1016 /$ j.envint.2009.07.010

Martino-Roth M.G., Viegas J. y Roth D.M. (2003). Occupational genotoxicity risk evaluation through the comet assay and the micronucleus test. Genet. Mol. Res. 2 (4), 410-417.

Ortega-Martínez L.D., Martínez-Valenzuela C., Huerta de la Peña A., Ocampo-Mendoza J., Sandoval-Castro E. y Jaramillo-Villanueva J. L. (2014). Uso y manejo de plaguicidas en invernaderos de la región norte del estado de Puebla, México. Acta Universitaria 24 (3), 3-12.

DOI: 10.15174.au.2014.570

Peralta L., Mañas F., Gentile N., Bosch B., Méndez A. y Aiassa D. (2011). Evaluación del daño genético en pobladores de Marcos Juárez expuestos a plaguicidas: Estudio de un caso en Córdoba, Argentina. Revista Diálogos 2 (1), 7-26.

Piperakis S.M., Petrakou E., Tsilimigaki S., Sagnou M., Monogiudis E., Haniotakis G., Karkaseli H. y Sarikaki E. (2003). Biomonitoring with the comet assay of Greek greenhouse workers exposed to pesticides. Environ. Mol. Mutagen. 41 (2), 104-110.

DOI: $10.1002 / \mathrm{em} .10143$
Piperakis S.M., Kontogianni K., Siffel C. y Piperakis M.M. (2006). Measuring the effects of pesticides on occupationally exposed humans with the comet assay. Environ. Toxicol. 21 (4), 355-359.

DOI: $10.1002 /$ tox.20191

Salazar-Moreno R., Cruz-Meza P. y Rojano-Aguilar A. (2012). Eficiencia en el uso de la energía en invernaderos mexicanos. Rev. Mex. Cienc. Agríc. 4, 736-742.

Sonneveld C. y Voogt W. (2009). Plant nutrition of greenhouse crops. Springer, Dordrecht Heidelberg, Países Bajos, 432 pp. DOI: 10.1007/978-90-481-2532-6

Srám R.J. y Binková B. (2000). Molecular epidemiology studies on occupational and environmental exposure to mutagens and carcinogens, 1997-1999. Environ. Health Perspect. 108 (1), 57-70.

Stich H.F. (1987). Micronucleated cells as indicators for genotoxic damage and as markers in chemoprevention trials. J. Nutr. Growth Cancer 4, 9-18.

Stich H.F. y Rosin M.P. (1984). Micronuclei in exfoliated human cells as tool for studies in cancer risk and cancer intervention. Cancer Lett. 22, 241-53.

Thomas P., Holland N., Bolognesi C., Kirsch-Volders M., Bonassi S., Zeiger E., Knasmueller S. y Fenech M. (2009). Buccal micronucleus cytome assay. Nat. Protoc. 4 (6), 825-837. DOI: 10.1038/nprot.2009.53

Tolbert P.E., Shy C.M. y Allen J.W. (1992). Micronuclei and other nuclear anomalies in buccal smears: A field test in snuff users. Am. J. Epidemiol. 134 (8), 840-850. DOI: 10.1016/0165-1161(92)90033-I

Wu C.W., Sun J.Q., Zhang A.P. y Liu W.P. (2013). Dissipation and enantioselective degradation of plant growth retardants paclobutrazol and uniconazole in open field, greenhouse, and laboratory soils. Environ. Sci. Technol. 47 (2), 843-849. DOI: 10.1021/es3041972 